\title{
O ENSINO DE LIBRAS EM SINALIZADORES OUVINTES: UMA ANÁLISE DOS PARÂMETROS FONOLÓGICOS
}

\author{
Luiz Antonio Zancanaro Junior * \\ Marianne Rossi Stumpf * *
}

\begin{abstract}
Resumo: Este trabalho apresenta uma análise das alterações nos parâmetros fonológicos durante a produção dos sinais em adultos ouvintes usuários da Libras (Língua Brasileira de Sinais) como segunda língua em período inicial de aprendizado da língua. A pesquisa apresenta uma análise das produções desses sinalizadores ouvintes, onde os parâmetros fonológicos de configuração de mão, locação e movimento foram recortados para a análise da pesquisa. A análise demonstra que o maior número de alterações fonológicas identificadas ocorreu no parâmetro configurações de mão, com raras trocas nos outros parâmetros.
\end{abstract}

Palavra-chave: Libras. Fonologia. Segunda língua.

\begin{abstract}
This paper presents an analysis of changes in phonological parameters during the production of signs in adult listeners users of Libras (Brazilian Sign Language) as a second language at an early period of language learning. The research presents an analysis of the productions of these signer listeners, where the phonological parameters of handshape, location and movement were cut for the analysis of the reserch. The analysis shows that the greatest number of phonological changes identified occurred in the parameter hand configuration, with scarce changes in the other parameters.
\end{abstract}

Keywords: Libras. Phonology. Second language.

\section{Introdução}

É de suma importância a conquista legislativa obtida pela comunidade surda no reconhecimento da Língua Brasileira de Sinais. A partir de então, mais ouvintes passaram a se interessar pela língua e também a frequentar cursos em nível de extensão com o intuito de aprender. Muitos destes, acadêmicos de cursos de formação de professores e fonoaudiologia, estão matriculados em disciplinas regulares obrigatórias de Libras, de acordo com o que regulamenta o decreto 5.626/2005. Entretanto, muitos destes alunos deixam de praticar a Libras, ocasionando em esquecimento e, por conseguinte, a sua sinalização produz distorções em alguns sinais, além da inadequação na transmissão da informação. Lembrando que no Brasil cresce o número das pessoas surdas com acesso às instituições de ensino superior, tanto públicas como privadas, e do acesso de pessoas ouvintes ao aprendizado da Libras, permitindo a comunicação com pessoas surdas, favorecendo a acessibilidade de qualidade na sociedade.

Pode-se dizer que a Libras como língua de modalidade visual-espacial exige do aprendiz ouvinte alteração de significação de uso nos órgãos da audição e da visão, passando o órgão da visão a ter função linguístico-comunicativa o que exige a anulação da audição como captadora de informação dessa natureza, diferentemente da Língua Portuguesa onde se exige primariamente a audição. Ao comparar as distinções entre as duas línguas, Leite e McCleary (2008) consideram a necessidade de maior atenção visual dos ouvintes na compreensão da Libras. Mais do que isso, estes aprendizes dispensam maior atenção às mãos

\footnotetext{
* Doutorando em linguística na Universidade Federal de Santa Catarina, Professor do Instituto Cenecista Fayal de Ensino Superior e e-mail: juniorlz18@gmail.com

* * Pós-doutorado na Universidade Católica Portuguesa, Professora da Universidade Federal de Santa Catarina e e-mail: stumpfmarianne@gmail.com
} 
do sinalizador ${ }^{1}$ nativo surdo do que as informações linguísticas presentes no rosto, nem sempre muito percebidas. Leite e McCleary (2008) observam que os surdos conversam de maneira distinta e ao mesmo tempo que focalizam especialmente o rosto do sinalizandor, percebem os sinais manuais em um amplo ângulo de visão, ao passo que, os aprendizes, em alguns momentos, além de focalizar o rosto, desviam o olhar para as mãos do sinalizandor, perdendo as informações faciais - como nos casos de soletração manual, desta forma é possível perceber que há diferenças no padrão de comportamento linguístico do sinalizador nativo surdo e do aprendiz Outro fator que também implica nas perdas de informação é o não acompanhamento visual das trocas de turnos dos sinalizadores, numa conversa em grupo. Da parte dos aprendizes, há a impressão de que a informação foi rompida, tendo em vista a dificuldade de acompanhar a sinalização de dois ou mais surdos que interagem ao mesmo tempo. Já os surdos, dialogam diversos tipos de assuntos sem a necessidade de redirecionamento da cabeça e do olhar de forma tão freqüente e/ou intensa. Isto acontece por conta da inabilidade de lidar com uma nova língua, de modalidade diferente da sua, inabilidade esta que faz parte do processo natural de aprendizado.

Uma vez tratando também da aprendizagem da Libras por pessoas ouvintes, a linguística das línguas de sinais insere também o conceito de segunda modalidade, conforme descrito por Pichler (2009). Quando um ouvinte decide aprender outro idioma oral-auditivo, ele está aprendendo uma língua de mesma modalidade. No entanto, os ouvintes que aprendem a língua de sinais como segunda língua podem encontrar, além das dificuldades naturais da língua, outras emitidas pela modalidade (visual-espacial). Nestes casos, aprendem não somente uma segunda língua, mas também uma segunda modalidade (doravante M2).

Percebe-se que as produções em Libras dos sinalizadores ouvintes como M2 possuem distorções em função da dificuldade motora das mãos. Essas dificuldades podem ser apresentadas nos segmentos dos parâmetros fonológicos, o que implica na alteração dos sinais. Possivelmente, isso se deve ao fato dos sinalizadores iniciantes começarem a aprender Libras como uma M2. Essa dificuldade pode ser entendida como um fator equivalente ao que acontece também com os usuários no aprendizado de línguas orais como L2, mas como modalidade M1.

Em suas tentativas na produção dos sinais e na visualização da sinalização dos surdos, os usuários ouvintes como M2 tentam adequar a forma correta de cada um dos itens dos sinais, de maneira que consigam produzi-las como se fosse um reprodução do surdo. $\mathrm{Ou}$ seja, as produções iniciais não são perfeitas, são apenas cópias da produção do surdo, com distorções por causa da dificuldade motora e da coordenação das mãos, ocorrendo apenas na forma de um ensaio para reprodução dos sinais.

Neste sentido, este trabalho de pesquisa tem por objetivo fazer um estudo da estrutura dos sinais produzidos pelos usuários de Libras como segunda língua (L2), analisar e descrever os sinais produzidos de forma distorcida por eles. $\mathrm{O}$ foco da pesquisa consiste nos três parâmetros da fonologia da Língua de Sinais: configuração de mão, locação e movimento, utilizando como referência os sinais produzidos no litoral catarinense.

\section{Teoria sobre a fonética e a fonologia das línguas de sinais}

Há muito tempo, as línguas de sinais eram vistas como apenas gestos ou pantomimas, nas quais não era possível expressar conceitos abstratos. Atualmente, ainda existe um grande preconceito e desconhecimento sobre as línguas de sinais, tendo em vista que as pesquisas na área são um pouco limitadas. Em 1965, Willian Stokoe publica o livro

\footnotetext{
${ }^{1}$ Conceito de sinalizador: pessoa que produz os sinais, emitindo uma mensagem durante a comunicação através da língua de sinais.
} 
Sign Language Structure, cuja obra explica de forma clara a naturalidade das línguas. Sua análise foi baseada em observações dentro da própria comunidade surda. Através de suas observações, as línguas não-orais passaram a ser incorporadas em suas pesquisas.

As línguas de sinais ganharam o status de línguas naturais e sociais na comunicação humana, com estruturas gramaticais e exercendo funções interacionais. As línguas de sinais possuem uma estrutura que obedece a simultaneidade na organização dos elementos, como o uso das mãos no espaço e no corpo, assim como os aspectos formacionais de um sinal encontrados na configuração de mão, localização e movimento. Ou seja, cada um dos elementos não ocorre isoladamente, como é o caso dos fonemas ${ }^{2}$ dentro das línguas de sinais que se articulam simultaneamente.

Da mesma maneira, as línguas de sinais apresentam-se em um espaço multidimensional, com elementos constitutivos em regime de simulteneidade, assim como existindo em linearidade na sua realização. Já as línguas orais são unidimensionais, como exemplo, a sequência de palavras, sua entoação e os traços distintivos dos fonemas, prevalecendo a não simultaneidade (BRITO, 1995).

As pesquisas de Stokoe (1960); Stokoe, Casterline e Cronenberg, (1965); Supalla e Newport (1978); e Klima e Bellugi (1979), foram os primeiros estudos sobre o nível fonológico da Língua de Sinais Americana (ASL), organizando principalmente, uma base teórica estruturalista. Esses autores propuseram registros e discussões acerca da validade dos parâmetros, ressaltando os diversos elementos das línguas de sinais como sendo constituídos de fonemas produzidos simultaneamente. Além disso, aceitaram a existência de sequencialidade na Língua de Sinais (como ressaltou Stokoe para o caso do parâmetro de movimento), enfatizando o aspecto contínuo dos elementos e a superposição dos mesmos na constituição dos sinais (BRITO, 1995).

Conforme descreve Brito (1995), existem dois modelos com a descrição do sinal ilustrado THINK em ASL, (veja a Fig. 1). Um é o modelo de transcrição apresentado por Stokoe et al (1969) e o segundo é o modelo proposto por Liddell e Johnson (1989) onde existem camadas e segmentos nos sinais, sendo que cada camada equivale à análise do nível fonológico de uma língua de sinais. De acordo com Brito, (1995, p. 32) "o que parece ser necessário investigar é a hierarquia existente entre eles e a hipótese, que ora levantamos, de que a tendência das línguas de sinais é a de se discretizar muito mais em termo de simultaneidade do que em termos de segmentos sequências".

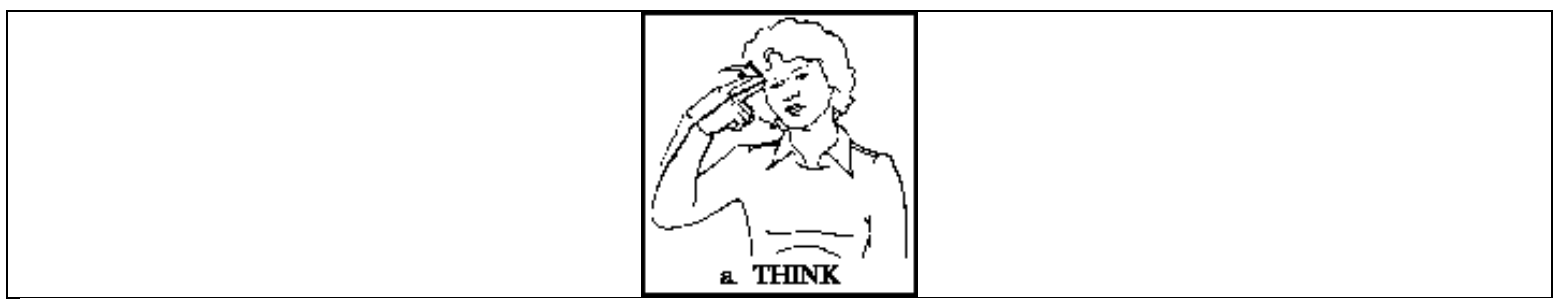

Figura 1 - O sinal "THINK (em port. Pensar)

Fonte: http://roseavenue.net/kelly/HumnetFiles/aslphonexer.htm

A Fig. 1 pode ser descrita como a mão direita em movimento para cima a partir de seu lugar de repouso. Quando se aproxima da testa, assume uma configuração de mão em G,

\footnotetext{
${ }^{2}$ A Libras não apresenta os sons. A fonologia das línguas de sinais se apresenta no corpo dos sinalizantes por meio da face e das mãos, e isso se deve ao fato de que as línguas orais e as línguas se sinais diferem pela sua modalidade. Stokoe, influenciado pelos estruturalistas americanos, denomina os três elementos unidos em um sinal como cheremes (queremas), de maneira análoga aos fonemas na língua falada. Através desse estudo, ele propôs o termo cherology (Quirologia), equivalente ao termo fonologia aplicado na lingusitica (QUADROS; KARNOPP, 2004; BRITO, 1995).
} 
com a ponta do indicador orientando-se na direção da testa, estabelecendo contato por um curto período de tempo.

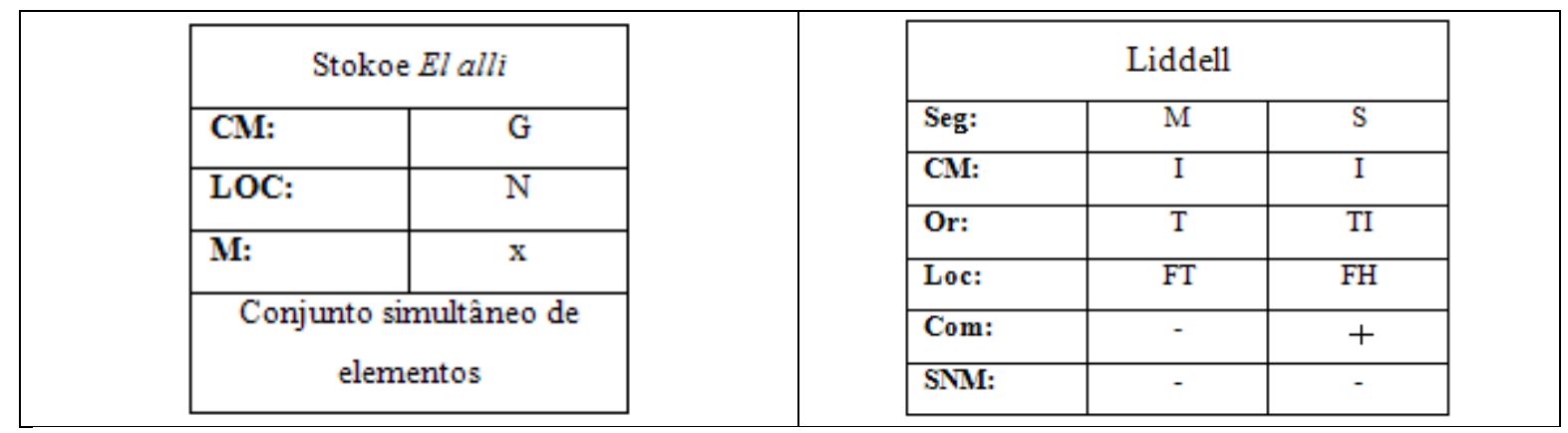

Figura 2 - Adaptação das transcrições em diferentes modelos. BRITO, 1995, p. 32.

Observarmos que os dois modelos aplicados apresentam as configurações de mão de $\mathrm{G}$ e I, ambas sendo iguais e mantendo um dos dedos estendidos e os demais flexionados. A configuração em I é a convenção utilizada por Liddell e Johnson (1989) para um tipo de CM, a qual Stokoe et al. (1976) denominam de G; N é o símbolo convencionalizado por Stokoe et al.(1969), enquanto FH é o símbolo usado por Liddell e Johnson (1989), sendo que ambos se posicionam na testa; e TI é a orientação da ponto do dedo para locação. O modelo tradicional de Stokoe et al. tem um movimento de contato x, já em Liddell e Johnson (1989) não há uma organização da parte relativa ao movimento, mas descrevem a sequência ocorrida neste sinal. A descrição do sinal THINK ${ }^{3}$ em ASL exposta por Liddell e Johnson, mostra que $\mathrm{Seg}^{4}, \mathrm{CM}^{5}$, $\mathrm{Or}^{6}, \mathrm{Loc}^{7}, \mathrm{Con}^{8}, \mathrm{SNM}^{9}$ se formam simultaneamente, portanto, não incorporando o movimento e a suspensão, que são sequenciais.

Liddell e Johnson (1989) ignoram a simultaneidade em suas pesquisas. Uma de suas propostas diz respeito ao movimento existente nos sinais, dessa forma possuindo três fases principais: (a) em suspensão no momento que a mão inicia o sinal; (b) a realização do movimento; e (c) o momento final, no qual a mão volta à condição de suspensão. Como alternativa de descrição, os autores desenvolveram um modelo conhecido como suspensãomovimento-suspensão, representado pelo esquema seguinte:

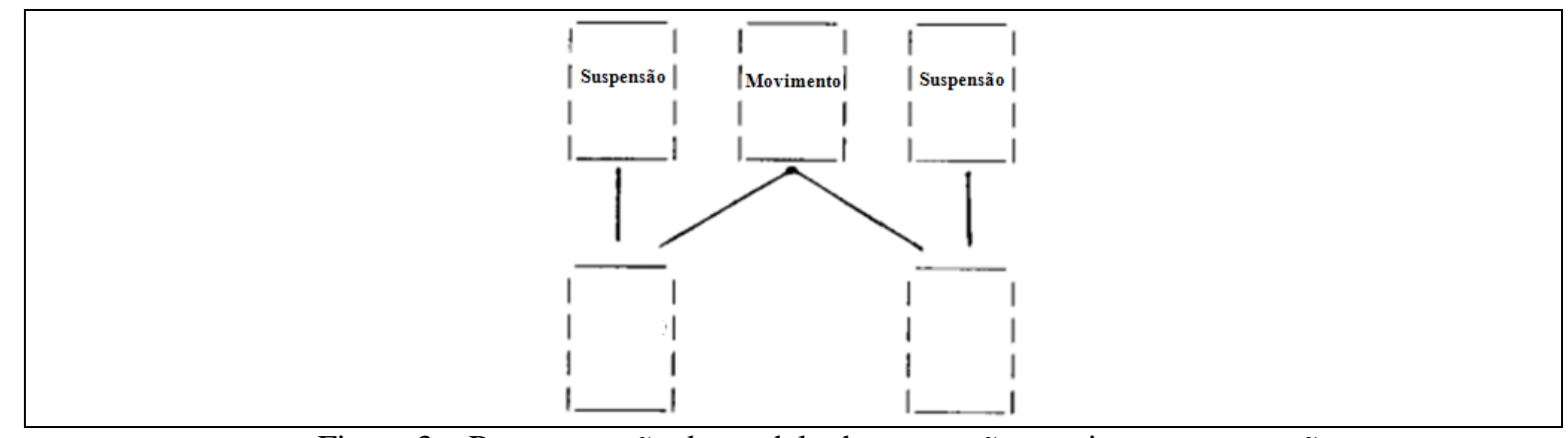

Figura 3 - Representação do modelo de suspensão-movimento-suspensão

\footnotetext{
${ }^{3}$ Seg: "Sequência". Parâmetro que envolve um ou mais segmentos, podendo ser movimento e/ou suspensão;

${ }^{4}$ CM: "Configuração de Mão". Representa o parâmetro sobre as várias formas que uma mão ou as duas realizam os sinais;

${ }^{5}$ Or: “Orientação de Mão". Diz respeito ao direcionamento da palma da mão;

${ }^{6}$ Loc: "Locação". Local onde os sinais são realizados no espaço a frente dele;

${ }^{7}$ Con: "Contato". Relativo a(s) mão(s) que toca(m) o corpo;

${ }^{8}$ SNM: "Sinal Não Manual”. Movimento(s) relizado(s) pela/na cabeça durante os sinais;
} 
Aqui apresentamos os vários tipos de sequencialidade nos sinais em ASL, incorporando sequências de configuração de mão, locação, sinais não-manuais, movimentos locais e movimentos de suspensão. Em um modelo simultâneo seria impossível representar de forma eficaz a estrutura do sinal com esses detalhes. Estes aspectos importantes da sequência dos sinais em ASL são capazes serem representados no dispositivo descritivo defendido por Liddell; Johnson (1989).

O modelo de estrutura sequencial dos sinais pode ser apresentada como uma correspondência aos segmentos fonológicos responsáveis pelo contraste sequencial e como uma forma de classificação também encontrada nas línguas orais. A existência dos segmentos linguísticos são demonstrados em menor unidade na ASL através de pares distintos - devido a sua sequência interna -, assim como visto na descrição de línguas orais.

Relacionando as teorias apresentadas com os dados desta pesquisa, conclui-se que é importante compreender, primeiramente, as diferenças estruturais na simultaneidade e sequencialidade do sinal. Nesta pesquisa, um estudo prévio a respeito dessas teorias favorece na análise dos dados, principalmente no que tange à descrição dos segmentos fonológicos da Libras, dessa forma, utilizando o modelo fonológico de movimento e suspensão proposto por Liddell e Johnson (1989). Como visto anteriormente, os sinalizadores apresentam a produção dos sinais, mas com alterações nos parâmetros fonológicos, que por sua vez, neste trabalho, serão descritos. Para isso, os trabalhos de Ferreira Brito (1995), Quadro; Karnopp (2004) e Liddell; Johnson (1989) serão utilizados como referência para as análises dos dados coletados nesta pesquisa.

\section{Metodologia de pesquisa}

Ao fazer uma análise linguística é importante considerar a modalidade, já que esta influencia na produção linguística, tendo em vista que as condições articulatórias, físicas e temporais de produção e percepção envolvidas devem nortear na adequação de um modelo ideal e necessário à analise dos dados.

Para isso, foram selecionados 6 participantes para a pesquisa, todos estudantes de bacharelado e licenciatura na graduação em Letras-Libras da Universidade Federal de Santa Catarina (UFSC), campus de Florianópolis. Como o curso possui quatro turmas, sendo os $1^{\circ}$, $3^{\circ}, 6^{\circ}$ e $8^{\circ}$ períodos no turno matutino, foram selecioandos três estudantes das turmas do $3^{\mathrm{a}}$ e $6^{\mathbf{a}}$ período. Todos estes alunos matricularam-se nas disciplinas de (i) Libras Iniciante, (ii) Libras Pré-Intermediário e (iii) Libras Intermediário lecionados por professores surdos. Para fazer o convite, conversarmos com duas turmas na UFSC. Em seguida, fizemos uma préseleção com os alunos que aceitaram participar da pesquisa, que filmaria apenas 6 participantes, sendo 3 homens e 3 mulheres, com idades entre entre 21 (vinte e um) e 52 (cinquienta e dois) anos, sendo que um deles tem um familiar surdo. Os partipantes não possuiam o Certificado Prolibras de Proficiência de Tradutor/Intérprete de Libras, bem como o Certificado Prolibras de Proficiência de Instrutor de Libras, além de nenhum deles atuar como intérprete de Libras em instituições. No entanto, um dos participantes já havia feito um curso de Libras antes do ingresso na graduação em Letras-Libras, porém, devido a falta de contato com surdos, havia esquecido alguns sinais.

Em suma, os resultados obtidos na análise dos dados permitiu verificar que todos os sinais foram produzidos de forma inadequada quanto aos parâmetros fonológicos. Dessa forma, serão descritos a estrutura dos sinais produzidos por este grupo.

Os instrumentos e procedimentos de coleta de dados envolvidos apresentaram-se em três etapas, sendo que cada uma delas será descrita a seguir. Na primeira parte, os itens lexicais de sinais foram ensinados aos participantes, que observaram os cartões das figuras 
representando diferentes campos lexicais dos sinais, tais como: óculos, café, cachorro-quente, lagosta, mentira, veneno, só. Estes itens foram selecionados, uma vez que cada um utiliza uma mão dominante e uma não-dominante ou duas mãos dominantes, além dos tipos de movimentos ${ }^{10}$ e de configurações de mão com formatos distintos. Além disso, pode-se perceber que a produçã apresenta distorções que ocorrem tambem por conta da iconidade ${ }^{11}$.

Inicialmente, este trabalho apresentou em sua proposta 34 sinais escolhidos, que são amplamentes utilizados no litoral catarinense pela configuração de mão com várias formas e níveis distintos, aos quais foram apresentados aos sinalizadores como teste. Na etapa de análise de dados e resultados, 07 itens lexicais permaneceram, uma vez que foram as análises mais relevantes de informação, apresentando as distorções que tangem a fonologia da Libras e ao seu estudo teórico. Os demais foram eliminados, tendo em vista que foram semelhantes a outros itens de sinais.

No caso dos participantes iniciantes, o pesquisador conversou previamente com eles para que primariamente recordassem os sinais. Muitas vezes os participantes fizeram perguntas sobre os diferentes sinais, já que em determinados casos, existe a variação de sinais, assim como seu uso dependendo do local e da comunidade surda com a qual cada um tem contato. Nesta tarefa não foram feitas filmagens, uma vez que estudaram o vocabulário.

Após o término da primeira tarefa, iniciou-se a segunda tarefa, onde os usuários produziram cada sinal por imitação do enunciador surdo, através do vídeo no Power Point e representados nos slides com itens lexicais dos sinais padronizados. Por fim, na terceira tarefa, os participantes produziram cada um dos sinais a partir da visualização de uma imagem correspondente ao sinal, sem, contudo ver o sinal. Além disso, a enunciaçãoo dos sinais e os testes aplicados foram filmados.

Optou-se por fazer a segunda e terceira tarefa como atividades distintas. Sendo que na segunda atividade os participantes reproduziriam o sinal de acordo com o vídeo mostrado, ou seja, a atividade envolvia apenas a "imitação" do sinal. Já na terceira tarefa, uma imagem era mostrada ao participante, que deveria sinalizar o referido objeto. Dessa forma, a terceira tarefa valeu-se da sinalização em si e do uso da memória dos participantes, já que deveriam recordar o sinal correspondente à imagem, já apresentado anteriormente a eles. Esta característica faz com que a atividade 3 tenha um nível de dificuldade maior que a anterior. Ressalta-se, porém que os itens lexicais foram apresentados isoladamente e foram utilizados os mesmos nas 3 tarefas.

A coleta dos dados foi registrada por meio de filmagens em três câmeras: uma na Web Cam embutida no notebook, outra na posição diagonal esquerda e outra na direita, o que facilita na identificação da produção das mãos. Quando um participante ficava no ângulo da Web Cam embutida no notebook, iniciava a gravação na câmera direita e na esquerda antes da gravação linear que determinava a sinalização em Libras. Para facilitar a edição, juntando as atividades com um programa que permitia a abertura simultânea dos três vídeos na tela do computador. Depois do término da gravação, foram extraídos os dados coletados, depois carregados no computador principal do pesquisador para análise da transcrição em Libras.

O software ELAN dispõe de ferramentas profissionais que auxiliam na criação de anotações complexas sobre o vídeo. Com o uso dele, pode-se criar um número ilimitado de anotações nas trilhas do vídeo, tendo como característica a possibilidade de transcrever as glosas, os comentários, além das descrições. Com esse sistema é possível visualizar até 4

\footnotetext{
${ }^{10}$ Para os tipos de movimentos são necessários a existência do objeto e do espaço. Nas línguas de sinais, o objeto e o espaço são representados pelas mãos do sinalizador (BRITO, 1990). O movimento dentro de um parâmetro mais complexo a ser descrito, envolve uma vasta rede de formas e direções (KLIMA; BELLUGI, 1979).

${ }^{11}$ Iconicidade: alguns dos sinais são formados icônicamente por apresentarem uma espécie de relação de referência entre a imagem real e a sua reprodução visual no sinal (KLIMA; BELLUGI, 1979).
} 
vídeos simultaneamente, os mesmos podem ser sincronizados em uma mesma imagem com ângulos diferentes, como na Fig. 4.

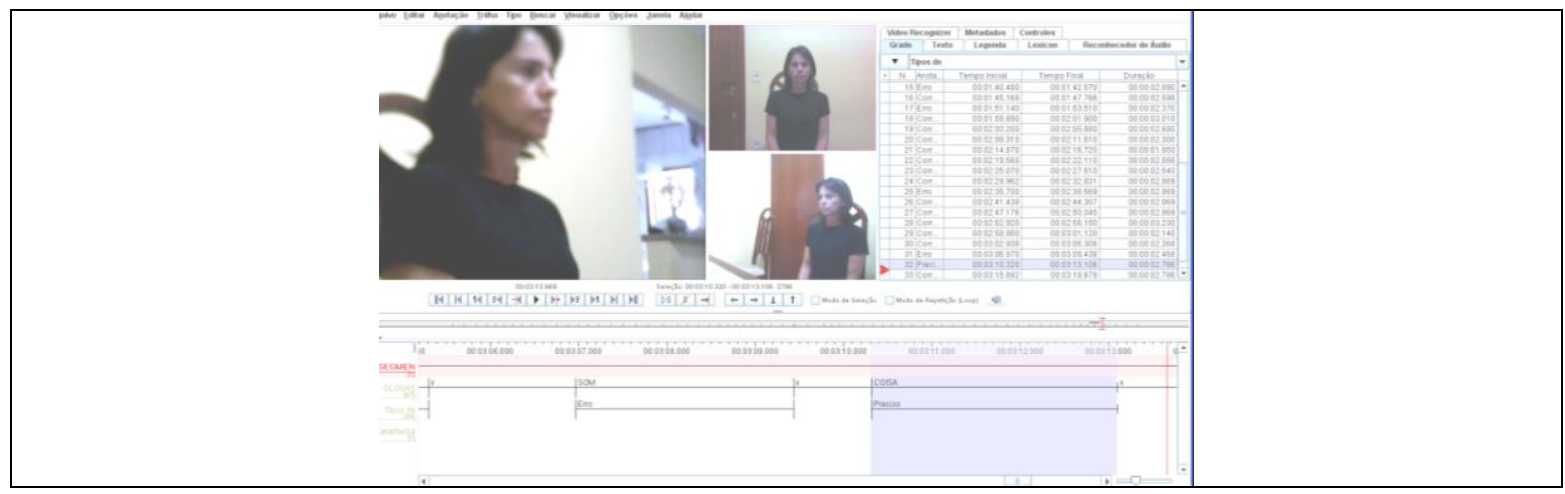

Figura 4 - Tela do ELAN

Para começar a análise, o sistema ELAN carregou os 3 (três) arquivos de vídeo (diagonal esquerda, diagonal direita, frente). Caso não seja possível visualizar os detalhes, cada vídeo pode ser rodado no tamanho da tela, facilitando a análise. Os vídeos podem rodar em velocidades diferentes, sendo que cada quadro apresenta as seguintes opções: começo do vídeo, final do vídeo, repetição do vídeo, avanço e retorno no tempo. Ao encontrar as distorções fonológicas mais complexas e que exigem uma análise mais minunciosa, cria-se uma trilha abaixo do vídeo denominada "DISTORÇÃO" uma vez que descreve a glosa referente aos itens lexicais selecionados desta pesquisa.

\section{Análise de dados e os resultados}

Nessa parte, apresenta-se uma descrição da sequência de observações dos aspectos articulatórios envolvidos na produção dos sinais e, essencialmente, analisa-se as distorções fonológicas durante a sinalização dos usuários, buscando verificar a estrutura dos itens lexicais. Para fins de aplicação dos conhecimentos, faz-se um estudo sobre a transcrição dos segmentos fonológicos e como funcionam sequêncial e simultaneamente no modelo de suspensão e movimento, proposto por Liddell e Johnson (1989) ${ }^{12}$.

A produção dos parâmetros fonológicos pelos usuários foi considerada quando examinadas e verificadas as semelhanças com o modelo apresentado pelo surdo adulto. Nesta perspectiva, buscou-se analisar a existência ou não da substituição, mais especificamente, em se tratando de configuração de mão, locação e o movimento, ou ainda a combinação destes elementos.

Com as informações coletadas nas filmagens iniciais e finais, foi possível fazer um recorte dos vídeos, separar as figuras apresentadas e o sinal produzido por cada usuário. A análise dos dados começa pela organização das filmagens em um corte transversal. Esse corte transversal auxilia na observação específica dos enunciados dos sinais, para, deste modo, verificar a possível estrutura naquele momento. Construiu-se uma tabela dos segmentos fonológicos considerando o ângulo frontal, sendo assim, não havendo necessidade de postar todos os segmentos, em todas as posições, já que, em alguns sinais, é possível perceber a produção em apenas um ângulo.

A delimitação do momento em que a articulação do sinal inicia e finaliza, é importante no sentido de estabelecer o número de segmentos constituintes do sinal. De acordo

\footnotetext{
${ }^{12}$ Para maiores informações ver o capítulo 2.3 que fornece detalhes de um sistema de transcrição de fonética na dissertação de mestrado de Luiz Antonio Zancanaro Junior (2013).
} 
com Xavier (2006, p. 118), "uma das mais complexas questões que surgem quando se tenta estabelecer a estrutura segmental de um sinal diz respeito à sua delimitação no continum sinalizado". Para o sinal, é uma tarefa complexa saber onde ele se inicia e finaliza.

Em seguida, pode-se ver os 7 (sete) diferentes sinais referentes do litoral catarinense utilizados na pesquisa e que foram observados pelos participantes nas tarefas. Na Fig. 5 exibido à esquerda da respectiva tabela, o sinal demostrado a seguir, pode-se observar o exemplo do sinal de "ÓCULOS", e à direita foi feita a análise do sinal produzido com as distorções feitas pelos participantes nas tarefas. Em seguida, abaixo da tabela, foi descrita a articulação do sinal do participante com a alteração fonológica inicial e final, o movimento e a locação acompanhados pelo modelo fonológico de suspensão e movimento por Liddell e Johnson (1989), com os recortes dos sinais realizados de maneira distorcida nas tarefas 2 e 3 respectivamente.

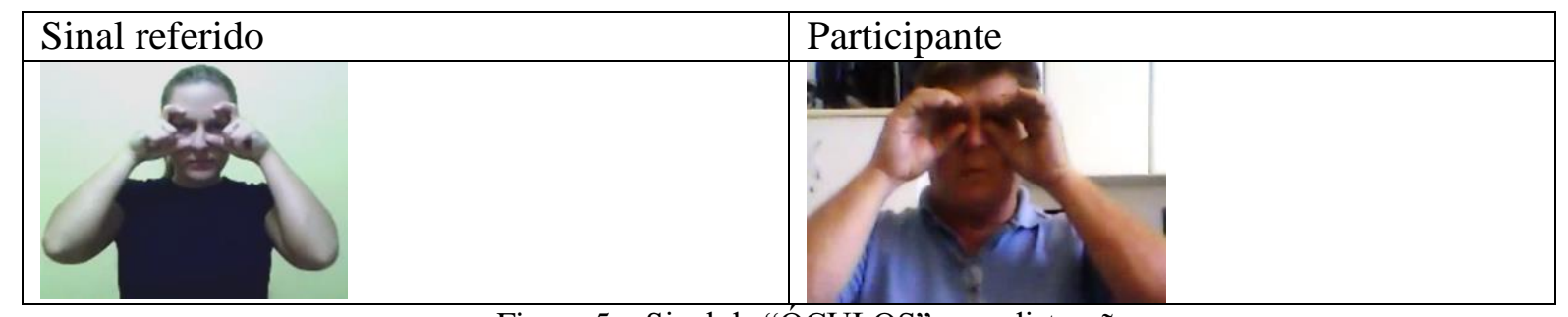

Figura 5 - Sinal de "ÓCULOS” com distorção

A Fig. 5 mostra a distorção na configuração de mão especifica [B" $\sim$ o] representado pelo modelo fonológico de Liddell e Johnson (1989) e que foi substituída, caracterizando sua postura de mão, pelos quatro dedos distendidos e espalmados que opõe a configuração de mão especifica [1" o ] do léxico referido do sinal. Lembrando que o usuário observou o vídeo com o sinal e em seguida fez sua produção, sem se dar conta de que a configuração de mão estava equivocada, produzindo um sinal diferente. Talvez a troca da configuação e consequentemente a distorção, tenha ocorrido por inflluência da iconicidade do sinal e pelo desconhecimento de que a distorção da configuração de mão daria a este sinal outro significado.

Essas configurações de mão de "B" e " 1 " são formas distintas, todavia, esse usuário fez a substituição do elemento, nesta perspectiva, as especificações da distorção cometida por ele são: a adução ${ }^{13}$ (os dedos unidos) e os demais dedos flexionados, visto que a forma de "B", que é considerada não marcada, parece mais fácil de ser manipulada.

\begin{tabular}{|l|l|l|l|}
\hline Sinal referido & Participante \\
\hline Participante 02 - tarefa 02 & Participante 02 - tarefa 03 \\
\hline
\end{tabular}

\footnotetext{
${ }^{13}$ A posição dos dedos espalhados ocorre em sinais dinâmicos e envolve os dedos selecioandos em uma ação, enquanto que para os sinais estáticos é essencial a adução dos dedos (dedos não espalhados), isto é, o dedo não se move durante a realização do sinal (KOOIJ, 2002).
} 


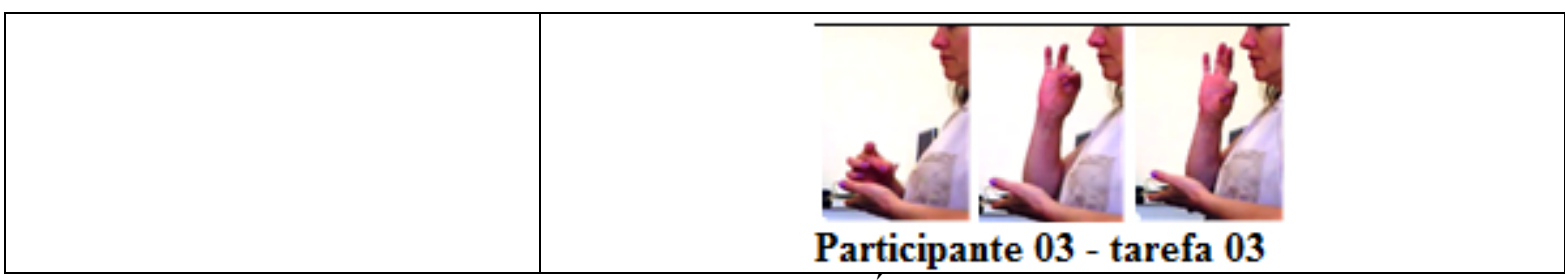

Figura 6 - Sinal de "CAFÉ" com distorção

A Fig. 6 apresenta o participante 02 realizando a tarefa 02 , onde a configuração inicial de mão do primeiro segmento é a mesma do sinal referente e a mesma da configuração de mão do último segmento substituído, representada por [A”op], como se pode observar o dedo indicador em contato com a almofada do polegar e os demais dedos enganchados.

Além disso, igura 6 mostra o participante 02 realizando a tarefa 03 ocorreu, onde a configuração de mão do último segmento foi substituída, representada por [9" op], caracterizada pelo dedo indicador em contato realizado na almofada do polegar. Observou-se que em cada atividade o participante cometeu uma distorção, ao que parece não percebeu a posição ideal dos dedos, utilizando, nas duas atividades, configurações de mão distintas.

A Fig. 6 onde o participante 03 apresenta a realização de uma distorção, uma vez que houve dificuldade de manipular os dedos selecionados corretamente. Esse dado levou a analisar que existem três segmentos de suspensões enquanto no sinal preciso exige apenas duas. Ocorreu uma nova inserção no último segmento de suspensão, a mesma configuração de mão do sinal preciso. Cada uma dessas sequências apresentou uma configuração de mão distinta, não afentado o significado. Apenas os dedos selecionados foram mudados, considerando que a dificuldade foi em imitar os dedos selecionados. Esse sinal, caracterizado pela configuração de mão do primeiro segmento e representado por [8"op], especifica o dedo médio distendido, o dedo indicador em contato com almofada do polegar e os demais enganchados. O segundo, representado por [U op], tem os dedos indicador e médio unidos, realizando o contato da almofada do polegar com os outros dedos juntos, a proximal distendida e a distal flexionada. O terceiro especifica em [9op] o dedo indicador em contato com a almofada do polegar e os dedos abertos e espalmados.

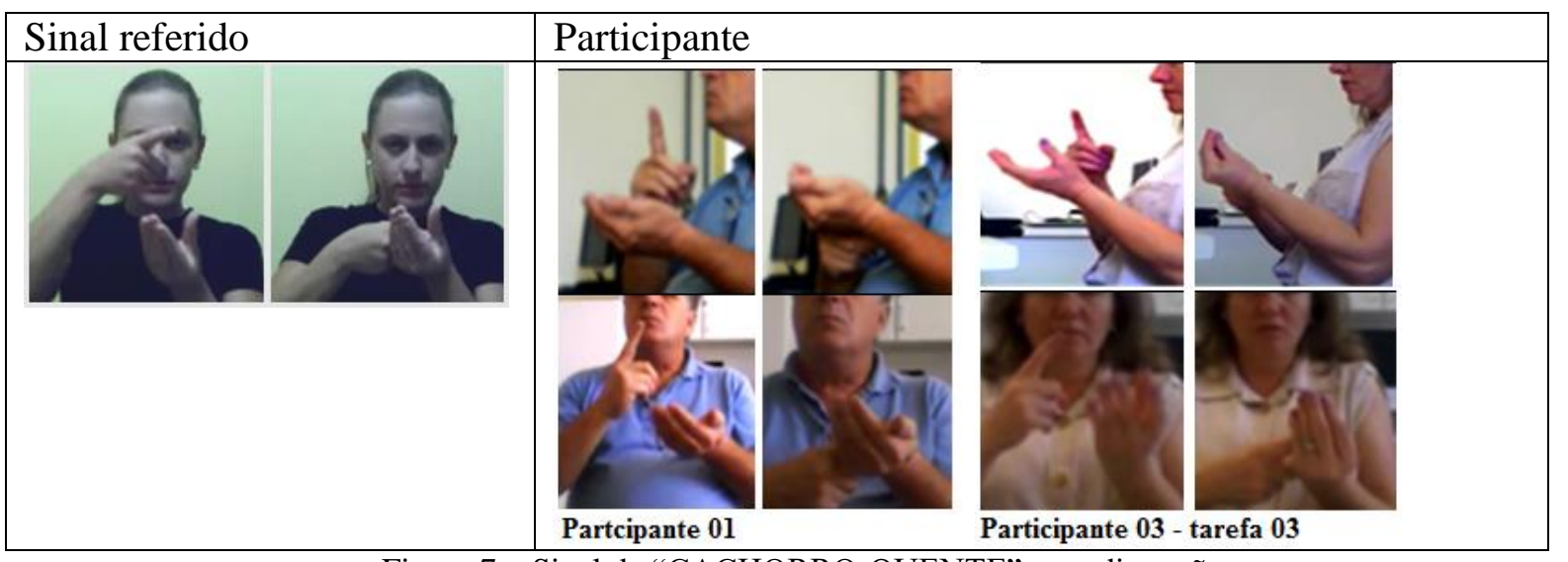

Figura 7 - Sinal de “CACHORRO-QUENTE” com distorção

A Fig. 7 mostra que o participante 01 produziu com a mão esquerda, na qual é substituída pela configuração de mão representada por $\left[\mathrm{Bu}^{\wedge}\right]$ : a palma aberta, os dedos unidos e o polegar não-oposto achatado em contato com a almofada do polegar. Esse sinal pode apresentar outro significado como "COMBINAR". As duas tarefas do participante 01 foram as mesmas, mas com configurações de mão especifica e distorcida.

A Fig. 7 mostra o participante 03, realizando o sinal demonstrado com a configuração de mão esquerda no segundo segmento, representada por $\left[\mathrm{B}^{\wedge} \mathrm{op}\right]$, isto é, os 
dedos achatados em contato com a almofada do polegar. O usuário produziu um sinal diferente do sinal referido, pois ele visualizou uma imagem do sinal referido e fez a imitação de forma idêntica, o que possibilita ser icônico pelo fato dele ter reproduzido os demais dedos distendidos tocando a ponta o polegar sobre a mão esquerda.

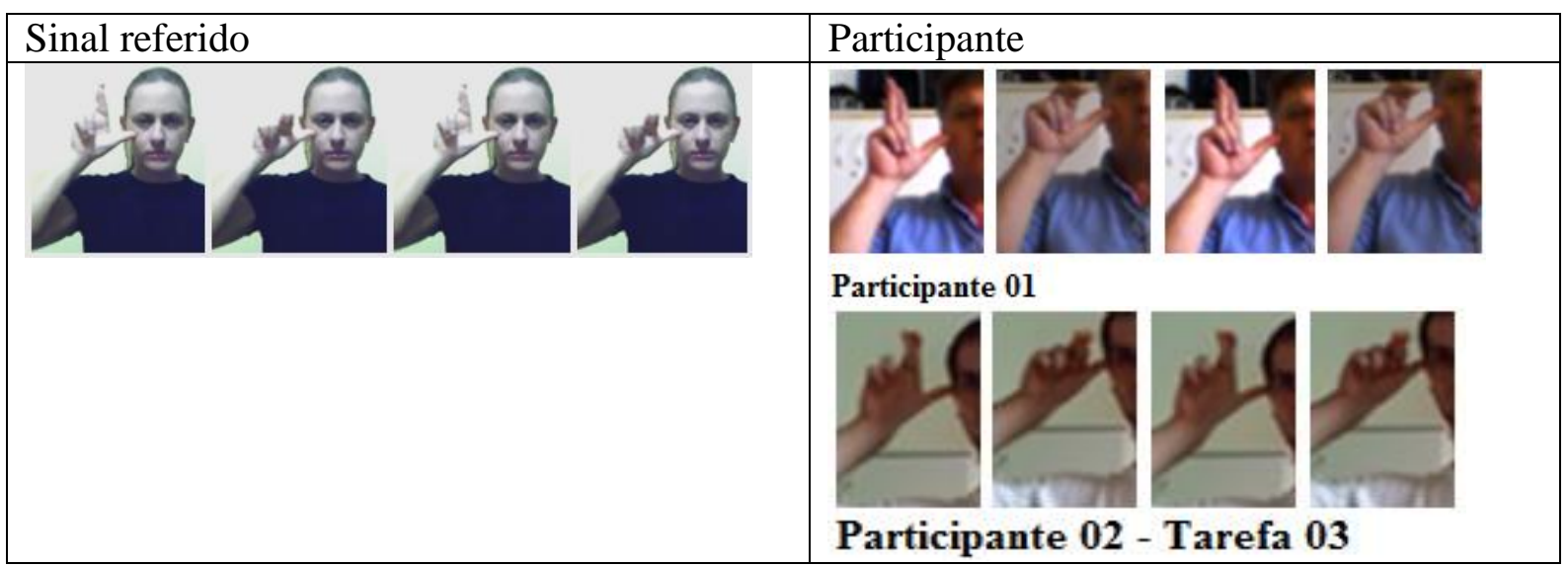

Figura 8 - Sinal de "LAGOSTA" com distorção

Na Fig. 8 todos os segmentos foram substituídos. Na configuração da mão, tanto o primeiro como o terceiro segmento de suspensão, representado por $[\mathrm{H}]$, isto é, os dedos indicador e médio distendidos e unidos e os demais fechados. Quanto ao segundo e quarto, representado por $\left[\mathrm{H}^{\wedge}\right]$, os dedos indicador e médio ficam unidos e achatados e os demais fechados, diferenciando-se da configuração de mão do sinal.

$\mathrm{Na}$ tarefa 03, o usuário produziu apenas dois segmentos, ou seja, pode-se dizer que ocorreu o apagamento do segmento fonológico, tendo em vista que o sinal tem quatro segmentos específicos. Percebe-se que o polegar não realiza o contato na bochecha, ficando um pouco distante, tendo uma substituição da locação. Totalizando 3 (três) ocorrências de configuração de mão distorcida.

O sinal "cavalo" produzido pelos usuários parece ter outro significado, pois, mudou na locação do sinal. No entanto, os dois sinais "LAGOSTA" e "CAVALO" têm as mesmas localizações, mudando apenas a configuração de mão, visto que nos dois casos os dedos indicador e médio se opõem.

Na Fig. 8, observa-se que foi substituída a localização, pois o traço de ponto de contato apresenta-se na ponta do polegar, representado por [TITH], em contato [c] com a porção superior da bochecha [CKt], já o polegar toca próximo da orelha, possibilitando o entendendimento dele como a forma da orelha de um cavalo ou dos braços de uma lagosta, que, por outro lado, torna-o um pouco confuso, exibindo um formato icônico, sendo o sinal parecido com o sinal de "CAVALO".

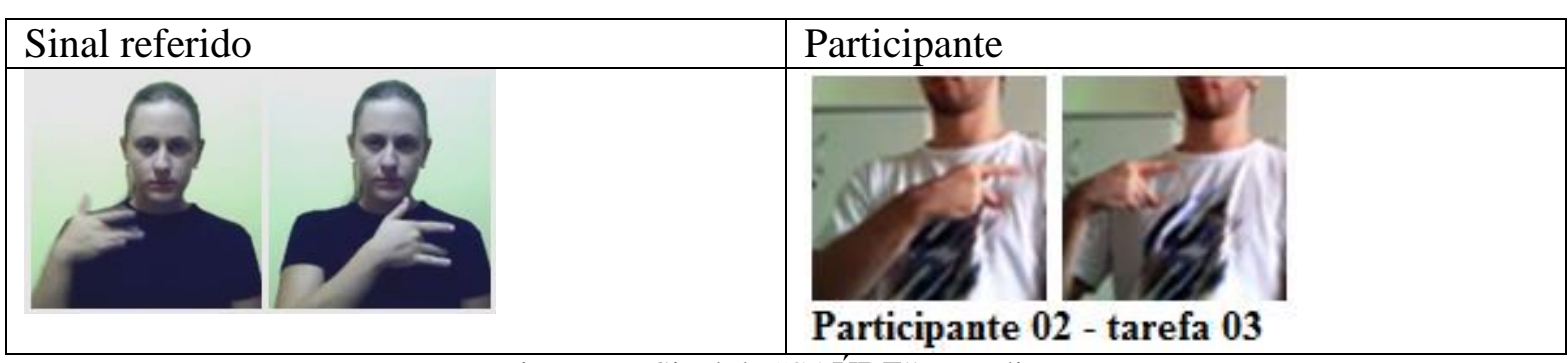

Figura 9 - Sinal de "SAÚDE” com distorção

Na Fig. 9 o que ocorreu foi a substituição da configuração da mão, simbolizada por [Vop], isto é, no polegar, a almofada entrou em contato com os dedos indicador e médio, 
distendidos, espalmados e com os demais dedos. Considera-se, portanto, o processo de movimento, no qual houve a reordenação desse sinal já que o segmento inicial foi substituído pelo final, neste sentido, o traço de ponto de contato mostrou a ponta de dedo médio tocando o peito contralateral $[\% \mathrm{CH}]$ no primeiro segmento, movendo-se no peito ipsilateral $[\mathrm{iCH}]$ no último segmento.

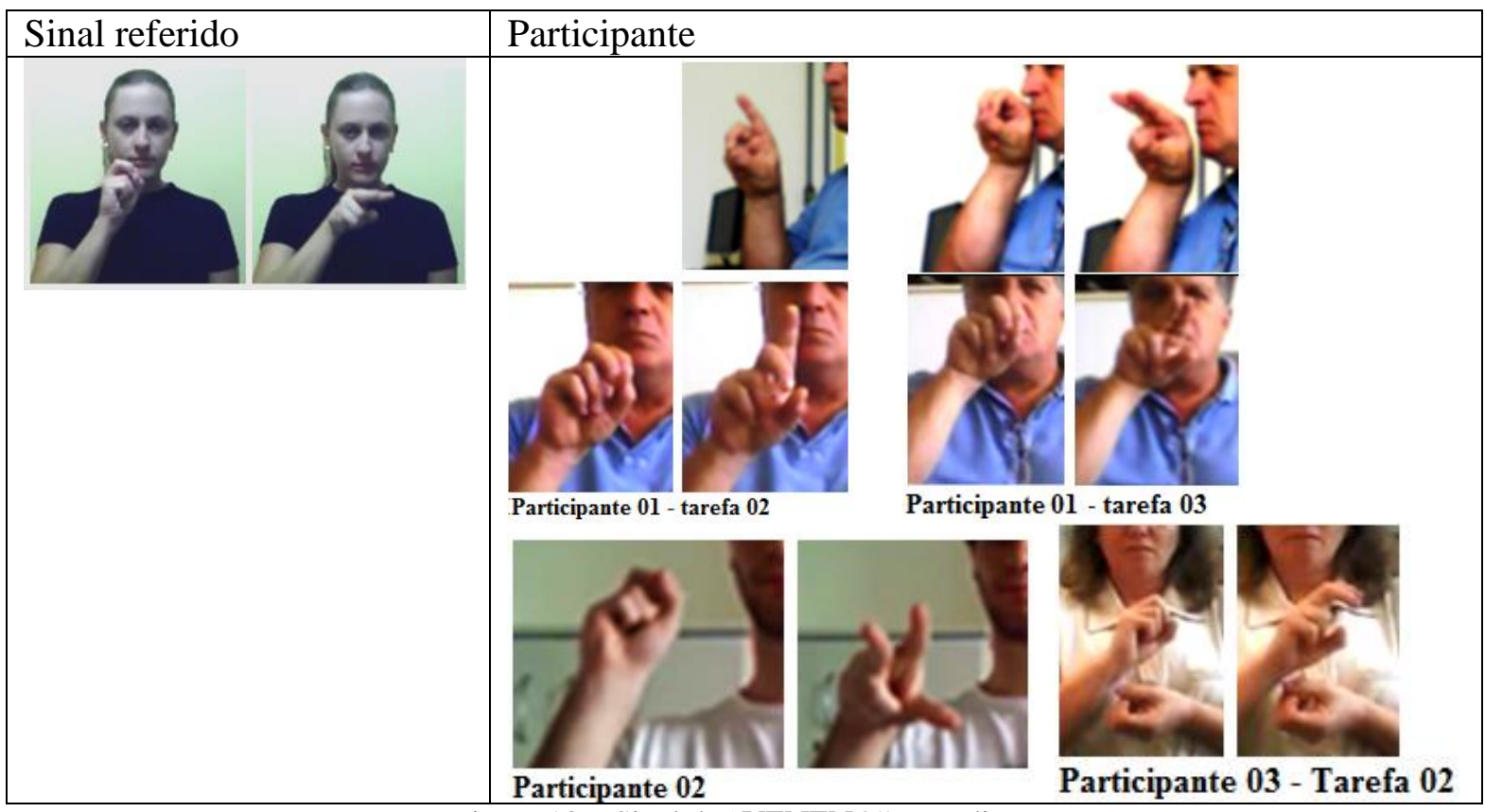

Figura 10 - Sinal de "VENENO" com distorção

Na Fig. 10, o participante 01 produziu o sinal distorcido na tarefa 02 . O usuário apresenta a primeira sequência da configuração de mão correta e a segunda como substituída. Para especificar, representa-se esse sinal como [Kco-], isto é, o contato realizado pela ponta do polegar ao dedo médio, o dedo indicador distendido e os dedos anelar e mínimo fechados. Esse sinal tem um movimento que se repete por duas vezes. A tarefa 03 ocorreu uma configuração da mão do primeiro segmento como a mesma apresentada. No entanto, houve um alteração no traço de ponto de contato nesse subfeixe, mas no que diz respeito à localização, ou seja, ao lugar em que esse sinal é articulado, na parte ipsilateral da boca. A configuração de mão do segundo segmento é substituída, e aqui representada como $\left[\mathrm{H}^{\wedge} \mathrm{o}\right]$, sendo que os dedos indicador e médio unidos e os demais dedos fechados. Nesse sinal houve a perda de um movimento, realizando apenas uma vez, o que parece dar outro sentido, lembrando o sinal icônico de "PATO".

Na Fig. 10, participante 02 produziu um sinal distorcido nas duas tarefas. O primeiro segmento é representado pela configuração [1fo-], onde o contato realizado pela almofada do polegar se dá na unha do dedo indicador distendido e os demais fechados. Aqui, foi substituída a configuração da mão no segundo segmento representado pela configuração desse sinal como $\left[\mathrm{V}^{\wedge} \mathrm{o}\right]$, ou seja, o polegar oposto aos dedos indicador e médio achatados e espalmados e os demais dedos fechados.

Na Fig. 10, o participante 03 produziu um sinal distorcido na tarefa 02 , onde se nota que o primeiro segmento desse sinal, caracterizado pelas duas mãos em condição simétrica, representado por [So-], isto é, o polegar fechado, oposto aos quatros dedos, também fechados e tocando as pontas na palma da mão. O segundo segmento é caracterizado por cada uma das mãos que não compartilham a mesma configuração, a mão dominante articula o movimento, que passa para o final, representado por [V"o-], isto é, o polegar fechado, oposto aos dedos indicador e médio enganchado e espalmado e os demais fechados. Em todos os segmentos foi 
substituída a forma da mão. Na tarefa 03, o usuário produz o sinal com apenas uma mão dominante, do início ao final do segmento, movendo-a de forma reta, na frente ao corpo, mas com a configuração de mão distorcida como na atividade 02 .

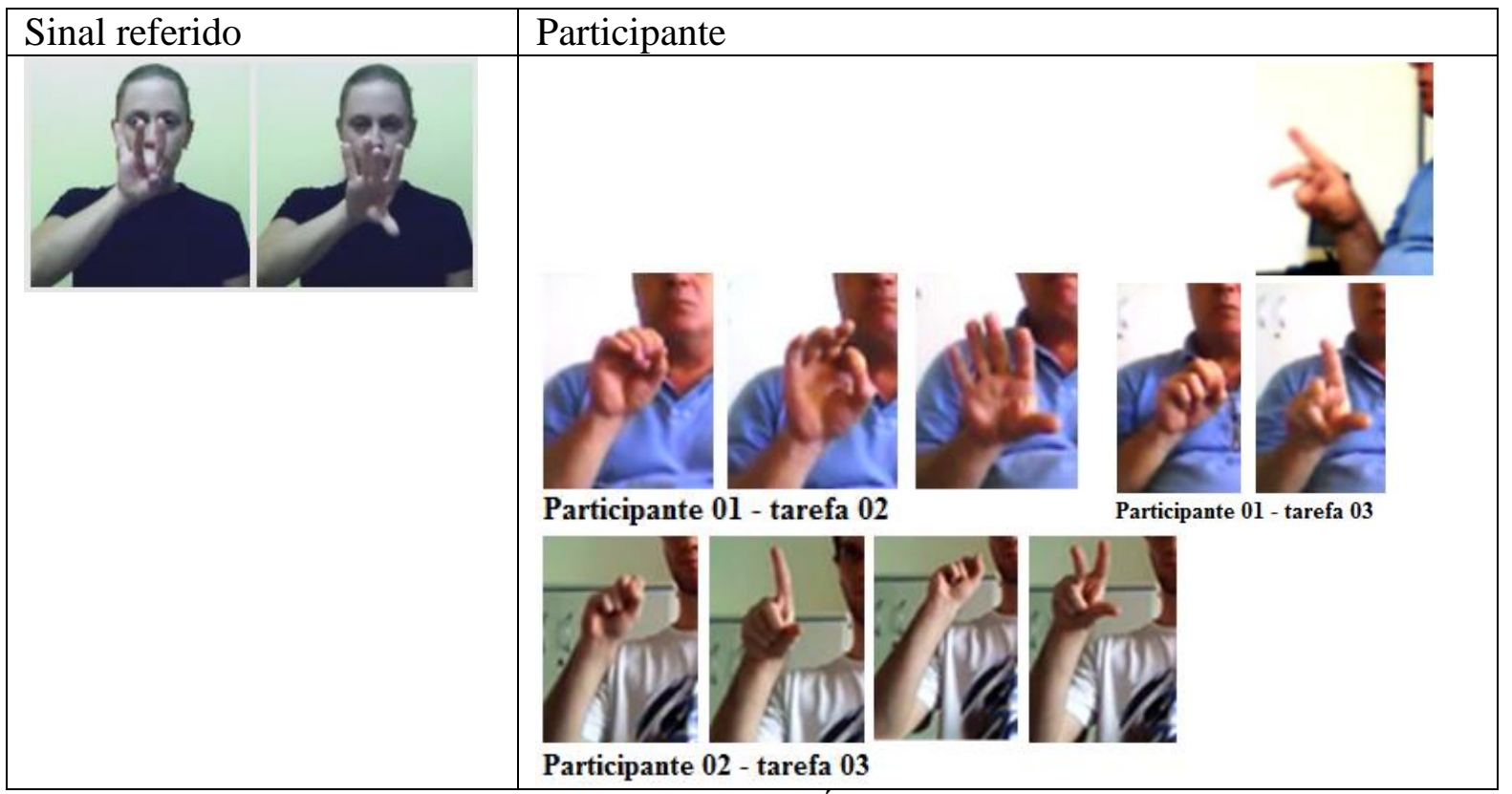

Figura 11 - Sinal de "SÓ” com distorção

Na Fig. 11, o participante 01 produziu o primeiro segmento da mão configurada na tarefa 02 , representada por [B" of], é o contato realizado pela almofada do polegar na unha dos dedos unidos e flexionados na junta proximal e distal; o segundo segmento da mão configurada foi substituído, representado por [9 op], caracterizado pelo dedo indicador em contato realizado na almofada do polegar e os demais dedos espalmados e flexionados na junta proximal e distal e o terceiro segmento da mão configurada, representado por [4o], isto é, os quatros dedos distendidos e espalmados e o polegar oposto como nova inserção do segmento de suspensão.

Na Fig. 11, o participante 01 produziu no segundo segmento da configuração de mão na tarefa 03 o que é representado por [K”o]. Dessa forma, vê-se os dedos anelar e mínimo fechados, o indicador distendido e o médio enganchado. Todas as configurações de mão foram substituídas.

A Fig. 11 apresenta um sinal no qual foram criadas novas inserções em dois segmentos: a primeira e terceira configuração de mão representadas por [So-], isto é, os quatros dedos fechados, tocando as pontas na palma, e o polegar fechado, tocando nos dedos; a segunda sequência, representada por [1o], isto é, dedo indicador distendido e os demais fechados com o polegar em oposição. Neste caso, o sinalizador 02 produziu duas vezes para ajustar a configuração de mão na tarefa 03.

Os três sinalizadores iniciantes apresentaram distorções fonológicas, cada usuário produziu 07 sinais, cada um dos sinais tem 3 unidades mínimas de parâmetros: configuração de mão, locação e movimento, deste modo, cada sinal tem posição inicial e final, assim, como a mão dominante e a não-dominante o que totaliza 21 itens nas duas tarefas. Alguns não conseguiram realizar a terceira atividade, pois esqueceram qual era o sinal correspondente à gravura, por isso, não foi considerado como distorção. Veja o Gráfico 1. 


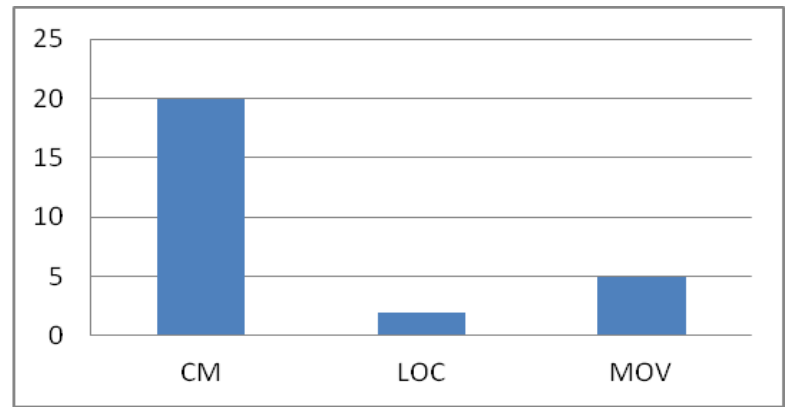

Gráfico 1 - Distorção dos parâmetros fonológicos

Pode-se observar, no levantamento apresentado acima, os números correspondentes: ocorreram distorções de configuração de mão em 20 das produções; no que se refere à locação, identificou-se 2 distorções; e com relação ao movimento, 05 distorções. Esses dados são mais uma evidência de que, entre os elementos fonológicos, as configurações de mão são mais complexas de serem reproduzidas do que as locações e os movimentos a partir da imitação da sinalização dos adultos surdos. Uma vez que, as configurações de mão envolvem diversas combinações de dedos e os sinalizadores iniciantes ainda precisam desenvolver uma prática motora com as mãos.

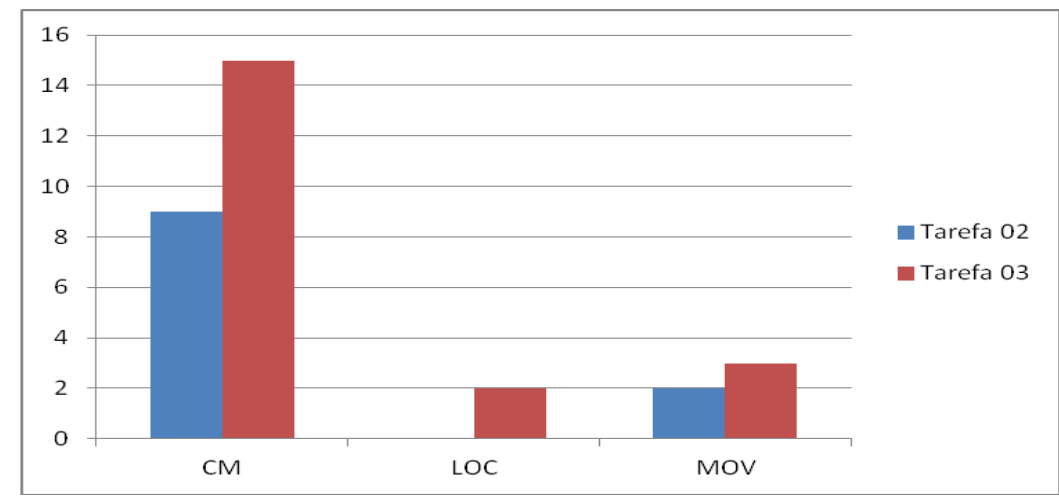

Gráfico 2 - Distorção nas tarefas

O Gráfico 2 mostra que na tarefa 02 ocorreram menos distorções do que na outra tarefa, uma vez que deveriam ver o vídeo e depois imitar o sinal visualizado. Nesta perspectiva, pode-se observar que a tarefa 02 não apresentou nemhuma distorção da locação, pois é fácil de percebê-la através da imitação do vídeo.

A produção em Libras dos participantes, resultou em um inventário dos parâmetros fonológicos específicos, sendo que na tarefa 02 teve menor índice de distorções fonológicas no momento de sua produção, pois o fato de usarem o vídeo como apoio facilitou na execução do sinal de maneita mais precisa. Na tarefa 02, observou-se que os usuários tem menos habilidades motoras com as mãos, que pode acontecer devido à pouca prática e contato recente com a língua. Os itens lexicais foram apresentados a eles através de vídeo e suas produções também foram filmadas para a análise. Notou-se uma dificuldade em perceber visualmente a configuração de mão apresentada, resultando em alteração fonética durante a produção do sinal.

A análise demonstrou que o maior número de alterações fonológicas identificadas ocorreram no parâmetro de configuração de mão, sendo raras as trocas no parâmetro locação e algumas trocas serem observadas no parâmetro movimento. A presente pesquisa expõe os sinalizadores ouvintes iniciantes, evidenciando um padrão de desenvolvimento da aquisição da língua de sinais. 
Assim, esse estudo do processo de aquisição de parâmetros fonológicos identifica padrões semelhantes aqueles apresentados por crianças surdas em processo de aquisição da Libras tal qual descrito por Karnopp (1999).

\section{Considerais finais}

O presente trabalho buscou trazer à comunidade linguística uma ajuda à descrição da Libras. Dessa forma, o estudo da estrutura interna da Libras apresenta uma gama infindável de possibilidades de análise dos sinais. A análise dos sinais é importante para identificação de aspectos que possam apresentar a ocorrência de distorções e alterações nos fonemas durante a sinalização dos usuários de Libras, além de uma análise entre os itens lexicais dispostos no vídeo sinalizado pelo surdo. Mais do que isso, é relevante compreender a organização da estrutura interna da Libras através das sequências durante a realização do sinal, desde o momento em que se inicia até sua finalização, investigando e identificando dados de distorções na produção dos sinais. Neste trabalho comprova-se a afirmação inicial de que os usuários iniciantes como M2 produzem menos distorções na tarefa 02 do que na tarefa 03 . A tarefa 02 os usuários produziram cada sinal por imitação do enunciador através da visualização previa de um vídeo e a tarefa 03 onde produziram cada um dos sinais visualizados no desenho, sem ver o sinal do vídeo, em vista de possuirem maiores dificuldades em habilidades motoras manuais, o que lhes exige prática contínua para a melhora na articulação dos sinais. Na tarefa 03, os participantes não possuiam o apoio do sinal correto e o usuário é estimulado a recordar os sinais que foram ensinados na tarefa 01 , podendo ocorrer um maior número de distorções.

\section{Referências}

BRASIL. Decreto $n^{\circ}$ 5.626, de 22 de dezembro de 2005, que regulamenta a Lei $\mathrm{n}^{\circ} 10.436$. Diário Oficial da República Federativa do Brasil. Brasília, DF. 22 dez. 2005.

BRITO, L. F. Por uma gramática de línguas de sinais. Rio de Janeiro: Tempo Brasileiro, UFRJ, 1995.

BRITO, L. F. Uma abordagem fonológica dos sinais da LSCB. Espaço $\mathrm{n}^{\circ} 1$. Rio de Janeiro: INES, 1990.

KARNOPP, L. B. Aquisição fonológica na Língua Brasileira de Sinais: Estudo longitudinal de uma criança surda. Porto Alegre, 1990. 273f. Tese (Doutorado) - Programa de Pósgraduação em Letras, Faculdade de Letras. Pontificia Universidade Católica do Rio Grande do Sul, Porto Alegre, 1999.

KLIMA, E.; BELLUGI, U. The Signs of Language. Cambridge, Massachusetts: Harvard University Press, 1979.

KOOIJ, Van der E. Phonological Categories in Sign Language of the Netherlands: The Role of Phonetic Implementation and Iconicity. Unpublished PHD dissertation, Leiden University. 2002. 
LEITE, T. A,; MCCLEARLY, L. Estudo em diário: fatores complicadores e facilitadores no processo de aprendizagem de língua de sinais brasileira por um adulto ouvinte. In: Quadros, R. M., Stumpf, M. R. (Orgs.). Estudos surdos IV. Petrópolis: Arara Azul, 2008. p. 242-277.

LIDDELL, S. K.; JOHNSON, R. E. (1989). American Sign Language: The Phonological Base. In: Valli, C.; Lucas, C. (Orgs.). Linguistics of American Sign Language: an introduction. Washington, D. C.: Clerc Books/Gallaudet University 2000. p. 267-306.

PICHLER, D. C. Sign Production by first-time hearing signers: A cliser look at handshape accuray. Gallaudet University. 2009.

QUADROS, R. M.; KARNOPP, L. B. Língua de sinais brasileira: estudos lingusiticos. Porto Alegre: Artmed, 2004.

STOKOE, W. C. et al. A Dictionary of American Sign Language on Lingusitics Principles. Silver Springer: Linstock Press, 1965.

STOKOE, W. C. Sign Language Structure: An outline of the visual communication System of the American Deaf. Studies in Linguistics: Occasional Papers, $n^{\circ}$ 8. Buffalo. University of Bufallo Press, 1960.

STOKOE, W. C; CASTERLINE, D.; CRONEBERG, C. A dictionary of American Sign Language on linguistic principles. Silver Spring, MD: Gallaudet College Press, 1976.

SUPALLA, T.; NEWPORT, E. How Many Seats in a Chair? The Derivation of Nouns and Verbs in American Sign Language, in P. Siple (ed) Understanding language Through Sign Language Reasearch. New York: Academic Press, 1978.

XAVIER, A. N. Descrição fonético-fonológico dos sinais da língua brasileira de sinais (Libras). São Paulo, 2006. 175f. Dissertação (Mestrado em Linguistica) - Programa de Pósgraduação em Semiótica e Linguística Geral, Faculdade de Filosofia, Letras e Ciências Humanas. Universidade de São Paulo, 2006.

ZANCANARO JUNIOR, L. A. Produções em Libras como segunda língua por ouvitnes não fluentes e fluentes: um olhar atento para os parâmetros fonológicos. Florianopolis, 2013. 192f. Dissertação (Mestrado) - Programa de Pós-graduação em Linguística, Centro de Comunicação e Expressão. Universidade Federal de Santa Catarina, 2013.

Recebido em: setembro de 2015.

Aprovado em: novembro 2015. 